

\title{
La transformación de un paisaje: el barrio Santa Inés en la ciudad de Bogotá
}

\section{Transformation of a Landscape: The Santa Inés Neighborhood in Bogotá}

\section{A transformação de uma paisagem: o bairro Santa Inês na cidade de Bogotá}

\author{
Jorge Armando Galindo Joya ${ }^{1}$
}

\section{Resumen}

El presente artículo es producto del proyecto de investigación Leer, sentir y vivir el paisaje de un lugar: el caso del barrio Santa Inés en la ciudad de Bogotá, desarrollado dentro de la línea de investigación Construcción Social del Espacio, de la Maestría de Estudios Sociales de la Universidad Pedagógica Nacional. El proyecto se sitúa en un enfoque cualitativo de corte interpretativo y etnográfico, acompañado de la Geografía de la percepción. Se utilizó el concepto de paisaje urbano como estrategia didáctica para la identificación, análisis e interpretación de los factores que han incidido en las transformaciones urbanas y sociales que presenta la zona de estudio (barrio Santa Inés) durante el período comprendido entre 1998 y 2010.

El artículo tiene como finalidad exponer algunos de los hallazgos y los aportes encontrados durante el desarrollo de la investigación, respecto a los factores de transformación urbana durante el período correspondiente a 1998 - 2010 y el análisis realizado.

\section{Palabras clave}

transformación urbana, paisaje urbano, ciudad y lugar 
La transformación de un paisaje: el barrio Santa Inés en la ciudad de Bogotá Jorge Armando Galindo Joya/

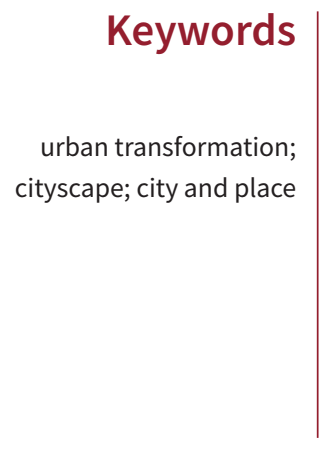

\section{Palavras chave}

transformação urbana, paisagem urbana, cidade e lugar

\section{Abstract}

This article is the result of the research project titled Reading, Feeling and Experiencing the Landscape of a Place: The case of the Santa Inés neighborhood in Bogotá, which was conducted as part of the research line on Social Construction of Space from the Master of Social Studies at Universidad Pedagógica Nacional. The research has a qualitative-interpretive and ethnographic approach, which is complemented with perception geography. The concept of urban landscape was used as a teaching strategy to identify, analyze and interpret the factors that have influenced urban and social transformations in the studied area (the Santa Inés neighborhood) from 1998 to 2010.

The purpose of this article is to present some findings and contributions made during the research regarding urban transformation factors from 1998 to 2010 and the analysis conducted.

\section{Resumo}

O presente artigo é produto do projeto de investigação intitulado: Ler, sentir e viver a paisagem de um lugar: O caso do bairro Santa Inês na cidade de Bogotá, desenvolvido na linha de investigação Construção Social do Espaço, do Mestrado em Estudos Sociais da Universidade Nacional Pedagógica. O projeto tem foco qualitativo de caráter interpretativo e etnográfico, acompanhado da Geografia da Percepção. 0 conceito de paisagem urbana foi utilizado como estratégia didática para a identificação, análise e interpretação dos fatores incidentes nas transformações urbanas e sociais que apresenta a área de estudo (bairro Santa Inês) durante o período entre 1998 e 2010.

O artigo visa expor algumas das descobertas e contribuições realizadas durante o desenvolvimento da investigação, com respeito aos fatores de transformação urbana durante o período de 1998 a 2010 e a análise realizada. 


\section{Introducción}

La investigación hace referencia a la transformación del paisaje urbano del barrio Santa Inés ${ }^{1}$, en la ciudad de Bogotá, y la cual podemos definir como los cambios morfológicos que se evidencian en el tiempo, como resultado de las diferentes dinámicas sociales y de las formas de actuar y pensar de quienes habitaron y habitan el lugar. Esto, con el fin de analizar los diferentes factores que en el paso del tiempo han intervenido en dicha transformación a lo largo del período correspondiente a 19982010, espacio de tiempo durante el cual se presenta la demolición de la mal llamada zona de El Cartucho, con el fin de construir el parque Tercer Milenio y otorgarle al lugar funciones recreativas y culturales diferentes de las que tenía, entendiendo los factores como elementos o circunstancias que contribuyeron o contribuyen a producir cambios o resultados.

En un nivel más específico, la investigación buscaba responder a la siguiente pregunta: ¿Qué factores han intervenido en la transformación del paisaje urbano del barrio Santa Inés en la ciudad de Bogotá en el período comprendido entre 1998 al 2010 ?

Para ello, se trazaron como objetivos:

- Analizar los factores que han intervenido en la transformación del paisaje urbano del barrio Santa Inés, de la ciudad de Bogotá, durante el período comprendido entre 1998 y 2010.

- Identificar los períodos de transformación urbana anteriores a 1998 que modelaron los cambios del paisaje urbano del barrio Santa Inés.

- Analizar los conflictos generados por los procesos de transformación urbana del barrio Santa Inés durante el período 1998-2010, a la luz de los períodos identificados de transformación urbana anteriores a 1998.

- Evidenciar los factores que intervinieron en el proceso de transformación urbana del barrio Santa Inés durante el período 1998-2010.

El interés que lleva a realizar este trabajo es reflexionar sobre el ejercicio de la construcción social del espacio respecto al paisaje urbano que lo configura, paisaje que es producto de las relaciones entre quienes lo construyen y lo habitan y las diferentes visiones urbanísticas y políticas públicas que en este se han desarrollado y las que en la actualidad se desarrollan, sea el caso de las políticas de renovación urbana de la ciudad de Bogotá planteadas desde el Plan Centro para la intervención de la zona de estudio desde finales de los años noventa del siglo XX y los comienzos del siglo XXI.

1 Parte del barrio se conoció desde los años ochenta hasta comienzos del siglo XXI como El Cartucho, un lugar degradado socialmente, en donde no tenían ninguna repercusión las decisiones del Estado ni las autoridades locales. La otra parte del barrio es lo que históricamente se conoce en la ciudad de Bogotá como San Victorino, lugar de ventas y comercio de diferentes artículos de procedencia legal o ilegal.
El uso de la etnografía y de la geografía de la percepción permitió realizar acercamientos al habitante del lugar, por medio de entrevistas y de la recolección de narraciones de fechas anteriores al período estudiado; se mantuvo una observación de campo constante en diferentes tiempos y momentos, registrada en fotografías y en diarios de campo que luego se contrastaron con fotografías y relatos de años pasados.

\section{Ruta metodológica}

El enfoque investigativo y metodológico abordado en el trabajo fue la etnografía, acompañada de la Geografía de la percepción como facilitadora de la lectura de lo urbano y del habitante de ciudad desde las representaciones mentales que va obteniendo de sus experiencias, y que se van proyectando en el paisaje urbano de los lugares.

Además, la percepción de lo urbano permitió obtener en la investigación una mirada cambiante y dinámica respecto a la transformación de lo físico y lo social en los paisajes que va adquiriendo cada lugar en determinada época, producto de las lógicas de poder del momento.

La manera como se recogió la información fue por medio de cinco instrumentos:

La revisión de archivos: instrumento que permitió el abordaje del primer objetivo específico, al identificar cinco períodos de transformación urbana que se presentaron en la zona de estudio desde su origen, durante la Colonia hasta finales del siglo XX, y que, a su vez, permitieron el reconocimiento y la interpretación de factores que incidieron e inciden hoy en el lugar, de índole social, político, legal y económico que han modificado el paisaje.

El registro fotográfico: es una herramienta que estimula la memoria del lugar y de los sujetos que lo habitan; la mediación de esta herramienta permitió captar imágenes de la realidad estudiada en un antes y un ahora, y ello facilitó la lectura de las transformaciones que presenta el paisaje del barrio.

Búsqueda y elaboración de mapas: por medio del programa ArcMap ${ }^{2}$, se construyeron mapas de la zona de estudio sobre: su ubicación y localización en la ciudad, delimitación del barrio, usos y dinámicas del espacio en los años cuarenta del siglo XX, mapas de contraste entre la zona antes y después de 1998 (año que marca el inicio de la construcción del parque Tercer Milenio), y un mapa de usos del suelo actual.

2 ArcMap es un conjunto de programas de procesamiento geoespacial, y se utiliza, sobre todo, para ver, editar, crear y analizar datos geoespaciales; permite al usuario explorar los datos dentro de un conjunto de datos que simbolizan las características de un lugar de acuerdo con las necesidades del mapa requerido. 
Entrevistas no estructuradas y semi-estructuradas: se efectuaron con ex habitantes, empleados del Instituto Nacional de Medicina Legal y habitantes de la ciudad que esporádicamente transitan por el lugar.

Las entrevistas significaron un acercamiento más detallado con el objeto investigado, permitieron obtener narraciones de tipo filial o topofóbico, dependiendo del tipo de experiencias que se hayan tenido con el lugar, por vía propia o de narraciones de otros que le van otorgando a la mente de los sujetos un contenido de cercanía o de distanciamiento. Las entrevistas no se realizaron de una forma estructurada y secuencial: en la mayoría de los casos fueron espontáneas, invitando al entrevistado a rememorar desde su percepción y su emotividad.
Los diarios de campo: instrumento indispensable en el registro y la organización de la información obtenida por medio de la observación, la cual, además de ser realizada por el investigador, también se efectuó con otras personas ajenas al lugar, quienes registraron su experiencia al recorrer la zona de estudio; esto con el fin de poder contrastar diferentes miradas de observación y percepciones.

Además de lo anterior, en la búsqueda de información y narraciones acerca del lugar se revisó el video: "Le gané la batalla al diablo en las calles del Cartucho", elaborado por la Fundación Rompiendo Cadenas. La figura 1 sintetiza lo anteriormente expuesto.

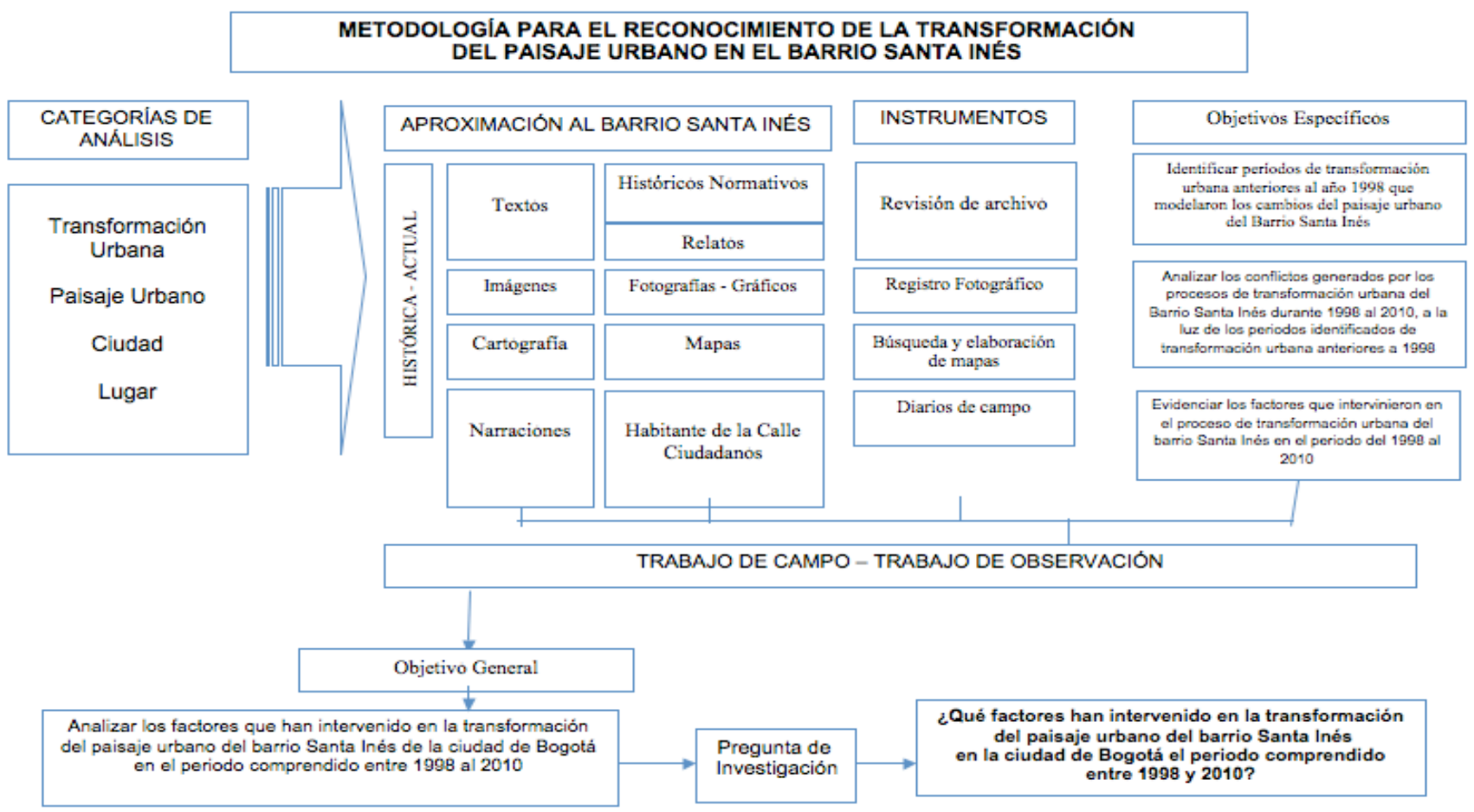

Figura1. Diseño de la investigación. Fuente: elaboración propia

\section{Reconocimiento de la zona de estudio}

La zona de estudio es el barrio Santa Inés, ubicado en la Localidad 3 Santa Fe, en la UPZ 93 Las Nieves, de la ciudad de Bogotá, entre la carrera Décima y la Avenida Caracas y la calle Sexta y la Avenida Jiménez, zona conocida como el parque Tercer Milenio y la senda comercial de San Victorino; cabe aclarar que esta última no es un barrio, sino un hito comercial que con el transcurrir del tiempo ha adoptado el nombre de la plaza que lo conforma, aunque en realidad es una parte del barrio Santa Inés, como lo indican el mapa de las UPZ elaborado por la alcaldía local en el año 2004, los mapas de la ciudad encontrados en la mapoteca de la biblioteca Luis Ángel Arango y la plancha número 100 revisada en Catastro.

La Localidad de Santa Fe se encuentra en la zona oriental de la ciudad. Comprende lo que se conoce como la ciudad antigua o el centro histórico, y su historia se remonta a la época colonial, durante la que se construyeron viviendas de estilo rústico-español que configuraron los primeros 
barrios de Bogotá: Santa Bárbara, Las Cruces, Las Aguas, La Veracruz, La Capuchina, Las Nieves, Santa Inés y San Bernardo; se destaca, además, el surgimiento del primer barrio obrero: La Perseverancia.

\section{Aproximaciones teóricas a lo urbano}

\section{La percepción: una interacción con lo urbano}

La percepción como campo de investigación no se mueve entre lo medible y establecido en el espacio desde los cánones académicos, sino que observa y estudia la realidad dentro de un escenario de acción social, como lo es lo urbano, estudiando lo diferente y lo cambiante en este, para poder ir al punto de tensión: las relaciones y las acciones de quienes habitan y transforman el espacio; en este caso, el espacio urbano, el cual está cargado de las emociones y los sentimientos que le otorgan quienes lo habitan, pues los seres humanos "sin emociones, (...) serían poco más que máquinas que trabajan de la misma manera día tras día. No conocerían los goces del amor ni la felicidad del éxito. (...) El orgullo, la envidia y los celos, serían desconocidos" (Whittaker, 1968, p. 107). Es así que las construcciones urbanas tanto físicas (calles, edificios, vías, casas, etc.) como mentales, son un reflejo del sentir de los sujetos.

De ahí la importancia que el sujeto, el habitante de la ciudad, comprenda y tome conciencia de su rol como ciudadano y de las implicaciones que sus acciones tienen en las transformaciones de la ciudad, por medio de las percepciones que sus sentidos le generan, de lo que lo rodea. Además, la ciudad no es la misma para todos: cada quien percibe y observa de diferente forma, dependiendo de su carga cultural y de sus modos de actuar, pues

(...) la mente humana no es un recipiente o un sistema de registro de la realidad. Es un agente activo y productivo que representa e interpreta, selecciona la información, toma lo que es importante y desecha lo demás. (...) Bailly asegura que damos a la información que recibimos una significación y un valor en relación profunda con nuestra personalidad y medio cultural, social y económico (González, 2004, p. 30)

En consecuencia, cuando se pasa por un lugar de la ciudad cada individuo recrea imágenes de una realidad particular que experimentó, o de realidades ajenas que se experimentan por medio de la comunicación con el otro, según la carga de significado que le haya otorgado quien comunica.

El objetivo de lo urbano debe ser mantener la diferencia, lo cambiante, por eso se habla de la percepción de lo urbano, del poder de percibir las diferentes construcciones sociales que se han ido tejiendo alrededor de este concepto y que van transformándose día a día con las acciones de los sujetos. "(...) lo urbano se define como lugar en el que las diferencias se conocen y al reconocerse se aprueban; por lo tanto, se confirman o se invalidan" (Lefebvre, 1970, p. 102).

\section{Lo urbano: proceso constante de transformación}

Al hablar de la transformación urbana, se hace mención a las diversas formas de entender la realidad, una realidad que es producto de las relaciones que se construyen entre los sujetos y van modificando la morfología del paisaje que les rodea. "(...) la morfología urbana, el espacio construido, reflejan la organización económica, la organización social, las estructuras políticas; los objetivos de los grupos sociales dominantes" (Capel, 2002, p. 20).

Desde mediados del siglo XX y comienzos del siglo XXI, las transformaciones en el paisaje de las ciudades han estado bajo las dinámicas de la modernidad, del avance tecnológico (Castells, 1974), escenario de transformación que ha llevado al olvido de las necesidades de los sujetos que lo habitan. En consecuencia, la transformación urbana va a ir tomando un mayor peso desde el mercado global, dejando de lado la calidad de vida de los sujetos. Sin embargo, es

importante señalar que la relación cultura-ciudad subyace si se quiere a los orígenes mismos de los estudios urbanos; más que una unidad económica, la ciudad ha sido vista como la manifestación suprema de la civilización y el producto de la cultura y el genio humano. (Montoya, 2006, p. 154).

No obstante, en un mundo cada vez más apresurado en sus dinámicas espaciales, el reconocimiento de la cultura y de la particularidad se descalifica ante el consumo y la innovación, por lo que, según menciona William Montoya (2007), es necesario

un reconocimiento de la cultura y la particularidad de la urbanización latinoamericana, porque los procesos urbanos experimentados por el primer mundo y el impacto de las nuevas tecnologías, un discurso de moda para interpretar múltiples realidades urbanas, no se expresan ni cualitativamente ni cuantitativamente en las ciudades de América Latina de la misma manera. (p. 10)

Debido a que las transformaciones dentro de las ciudades latinoamericanas no han sido pensadas desde la creación de un ambiente propio, la teoría urbana contemporánea busca la homogenización de los procesos de acción y comprensión del paisaje urbano.

\section{El paisaje urbano: una construcción social}

El concepto de paisaje urbano ha resignificado su sentido y su intencionalidad, con base en los contextos en los que ha sido punto de discusión y de configuración social; empieza a tener entrada dentro de las Ciencias Sociales a comienzos del siglo XX, como el concepto para mediary asegurar una identidad frente a la amenaza de una división entre la geografía física y humana, y aunque su análisis surge de forma cualitativa, se va a centrar en el estudio del plano desde dos aspectos básicos: la localización concreta del núcleo urbano y el plano como reflejo de las etapas de crecimiento de la ciudad. 
Empero, la potencialidad cualitativa que le fue otorgado al paisaje en el pasar del tiempo prueba cómo las palabras se resignifican cada vez que se re-contextualizan, cada vez que las formas de pensar y actuar de los sujetos se reestructuran, lo cual no permite la existencia de una estructura preestablecida. De ahí que "la trama urbana refleja con gran precisión cómo en la construcción de la ciudad se aplican diferentes filosofías; las ciudades de la Europa reconstruida tuvieron que aceptar una filosofía de guerra" (Fernández, 1990, p. 78), en distintos momentos de su historia, a causa del pensamiento y los intereses de determinada época que se expresan en las huellas de un paisaje en permanente transformación morfológica.

Luego, el concepto de paisaje urbano es una herramienta o un elemento de comunicación que permite identificar los usos y las formas de relacionarse de los sujetos con el espacio en diferentes tiempos. Según Harold Carter (1974):

(...) se ha divido la complejidad del paisaje urbano en tres componentes: el plano de calles o trazados, estilo arquitectónico o edificación y función o uso del suelo; estos componentes o partes se hallan estrechamente relacionados y, sin embargo, en los estudios académicos su separación ha conducido a tergiversaciones de la realidad. (...). Pero a fines (...) en la comprensión por la simplificación de la realidad, es preferible adoptar este fallo estándar en primer lugar y considerar cada uno de los tres componentes del paisaje urbano por separado. (...). Debido a que plano, edificación y uso del suelo se reaccionan en forma diferente frente a las fuerzas portadoras del cambio que les incumbe. (p. 155)

Esta forma de asumir el paisaje urbano se presenta específicamente desde el campo de la arquitectura y la medición, a causa de los planteamientos teóricos de la geografía para la década de 1960, que en algunos casos se encasillaban en una mirada física y cuantitativa que no permitía trascender a las relaciones sociales y económicas que dinamizan y problematizan la transformación de este paisaje. No obstante, Carter (1974) señala la importancia de analizar de forma separada cada componente, para luego poder contrastarlos, y así

(...) desistir de una vez y para siempre de aprender, repitiendo, los nombres de las ciudades, productos y puntos de interés como hechos aislados y optemos por un conocimiento general y comprensivo de su distribución espacial y de las consecuencias lógicas de su localización geográfica. La sustitución de la descripción por interpretación de la localización estableció los principios para que la geografía urbana progresase como un estudio especial. (p. 11)

El paisaje urbano no es un elemento más del espacio ni un conjunto de edificios organizados o desorganizados, sino que es un producto del sentir y el actuar de los sujetos que habitan y se relacionan en un lugar que va cambiando con el tiempo, “(...) es una especie de palimpsesto ${ }^{3}$, que como en un manuscrito que conserva huellas de una escritura anterior, hay en él partes que se borran y reescriben o reutilizan, pero de las que siempre queda huella” (Capel, 2002, p. 20), es “(...) un paisaje que se escritura sobre otra cosa, es un conjunto de objetos con edades diferentes, una herencia de muchos momentos diferentes (Real, 2009, p.16).

\section{El lugar: una experiencia con el paisaje}

"Los lugares son los espacios de relación más íntima entre la naturaleza natural, la naturaleza construida, las relaciones sociales y las significaciones culturales" (Montañez, 2001, p. 27). Es decir, el lugar es un espacio vivido, percibido y representado ${ }^{4}$, que se naturaliza por medio de las subjetividades y las relaciones a las que cotidianamente están adheridos los sujetos, y que generan en cada uno fobias y filias, consecuencia del contenido afectivo de afiliación o de negación que va adquiriendo el ser humano en el momento en que comparte y dialoga con el otro o consigo mismo en un espacio fijo, debido a que “(...) las personas siempre sitúan sus acciones en un lugar, las cuales son influenciadas por la naturaleza de éste" (Páramo, 2007, p. 69), como la vivienda, el parque, el centro comercial, el trabajo; o lugares más íntimos, como el cuarto, el baño o el mismo hombre. Un compartir que, al parecer, es necesario en la mayoría de los casos, de una forma innata, si bien es algo que no se puede afirmar con seguridad, pues la conducta humana es ininteligible.

(...) la identidad de la persona se construye no simplemente por las relaciones del individuo con otras personas sino también a partir de las relaciones de uno mismo con los diferentes escenarios físicos que definen y estructuran la vida diaria. En apoyo a esta aseveración, Proshansky et al., hace énfasis en el impacto negativo que producen (...) el deterioro del vecindario y su impacto en la auto-identidad. Un caso más concreto (...) es el sentimiento de desarraigo que viven las personas que han sido desplazadas de sus lugares normales de residencia, por efectos de la violencia (Páramo, 2007, p. 76).

Pese a lo anterior, el papel dominante que manejan hoy la información y la comunicación no permite ser consciente de este tipo de lecturas del contexto acerca de los lugares. Se han globalizado todos los aspectos de la vida social en el orden habitual de las personas, envueltas ahora en nuevas dimensiones, donde no se percibe con facilidad el diálogo tanto individual como grupal entre los individuos con los lugares, los cuales le pueden evocar al sujeto recuerdos.

3 La palabra palimpsesto es entendida dentro de la investigación como huellas que van quedando adheridas al paisaje urbano y permiten evidenciar acciones sociales anteriores a las que se le superponen acciones sociales actuales.

4 El espacio percibido se entiende como el espacio que resulta del contacto directo de un sujeto con un objeto especifico de conocimiento. El espacio representado hace referencia a la evocación que el individuo realiza de un objeto que ya ha conocido y manipulado. 
El lugar es todos aquellos sujetos que lo conforman; acabar con un lugar, demoler edificaciones, es también demoler recuerdos, significados y el hogar de quienes lo habitaban. Al hablar de las transformaciones del lugar, estas deben permanecer atentas a no violentar la identidad del mismo, es decir, a no violentar a quienes lo habitan, porque "los lugares son aspectos fundamentales de la experiencia de las personas en el mundo; son fuentes de seguridad e identidad tanto para los individuos como para los grupos de personas" (Páramo, 2007, p. 70).

El lugar, ante todo, es un espacio vivido en donde,

el efecto de vivir aquí o allí es más que la simple cuestión de dónde estamos, pues incluye cómo vivimos, dónde trabajamos, con quiénes nos relacionamos, cómo transcurre nuestro tiempo, cómo nos sentimos con relación a otros, qué recursos tenemos y hasta con qué poder contamos. (Montañez,2001, p.28)

\section{Resultados de la investigación}

\section{Períodos de transformación urbana}

El primer objetivo específico de la investigación señalaba la identificación de los períodos de transformación urbana anteriores a 1998 que modelaron los cambios del paisaje urbano del barrio Santa Inés; tal objetivo llevó a identificar cinco períodos, comenzando con el origen del barrio para el siglo XVI hasta finalizado el siglo XX, con el inicio de la construcción del parque Tercer Milenio.

\section{Matriz de identificación de períodos y factores de transformación urbana del barrio antes de 1998}

\begin{tabular}{|c|c|c|c|}
\hline $\begin{array}{l}\text { Entre iglesias y } \\
\text { creencias }\end{array}$ & XVII & 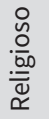 & $\begin{array}{l}\text { La necesidad colonial de evangelizar y dogmatizar a los habitantes del Nuevo Reino de Granada, creó una } \\
\text { morfología del paisaje de corte religioso que generaría en sus habitantes formas de actuar y pensar enfocadas } \\
\text { en la sumisión. }\end{array}$ \\
\hline \multirow{2}{*}{$\begin{array}{l}\text { Entrada y } \\
\text { aumento de } \\
\text { población }\end{array}$} & \multirow{2}{*}{ XVIII } & $\begin{array}{l}\frac{0}{0} \\
\frac{0}{0} \\
\frac{0}{0} \\
\frac{0}{0} \\
\end{array}$ & $\begin{array}{l}\text { El aumento de personas de diversos lugares del país por causas de la violencia llevó a convertir la zona en un nodo } \\
\text { poblacional de entrada y salida, debido a que era el lugar que comunicaba a la ciudad con el resto de lugares del } \\
\text { país por la vieja vía a Honda, que se comunicaba con el puente de Aranda. }\end{array}$ \\
\hline & & $\frac{\bar{\pi}}{\frac{\pi}{4}}$ & $\begin{array}{l}\text { La constante entrada de personas aumentó rápidamente la cantidad de residentes en el barrio, lo que, a su vez, } \\
\text { llevó a complejizar las relaciones sociales, pues eran personas de diferentes niveles sociales. }\end{array}$ \\
\hline \multirow{3}{*}{$\begin{array}{l}\text { Una aldea } \\
\text { empezaba a } \\
\text { vestirse de } \\
\text { ciudad }\end{array}$} & \multirow{3}{*}{ XIX } & 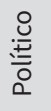 & $\begin{array}{l}\text { El paisaje urbano de la ciudad capital para el siglo XIX empieza a evidenciar en su arquitectura el paso de lo colonial } \\
\text { a lo republicano; este último, reflejo de libertad y autonomía del pueblo colombiano ante la corona española. }\end{array}$ \\
\hline & & 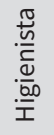 & $\begin{array}{l}\text { Procesos de higienización en la ciudad a finales del siglo XIX y comienzos del siglo XX. El país se insertaba en un } \\
\text { proceso de incorporación a la economía mundial y concebía la higiene como un instrumento de modernización } \\
\text { y de progreso. }\end{array}$ \\
\hline & & 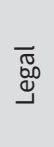 & $\begin{array}{l}\text { La ley de desamortización de manos muertas para } 1861 \text {, establecida por el presidente Tomás Cipriano de } \\
\text { Mosquera, expropió de sus bienes a las comunidades religiosas del territorio colombiano, con el fin de hacer } \\
\text { una liberación del suelo y darle una mejor funcionalidad que permitiera obtener mayor cantidad de regalías } \\
\text { para el Estado. }\end{array}$ \\
\hline
\end{tabular}




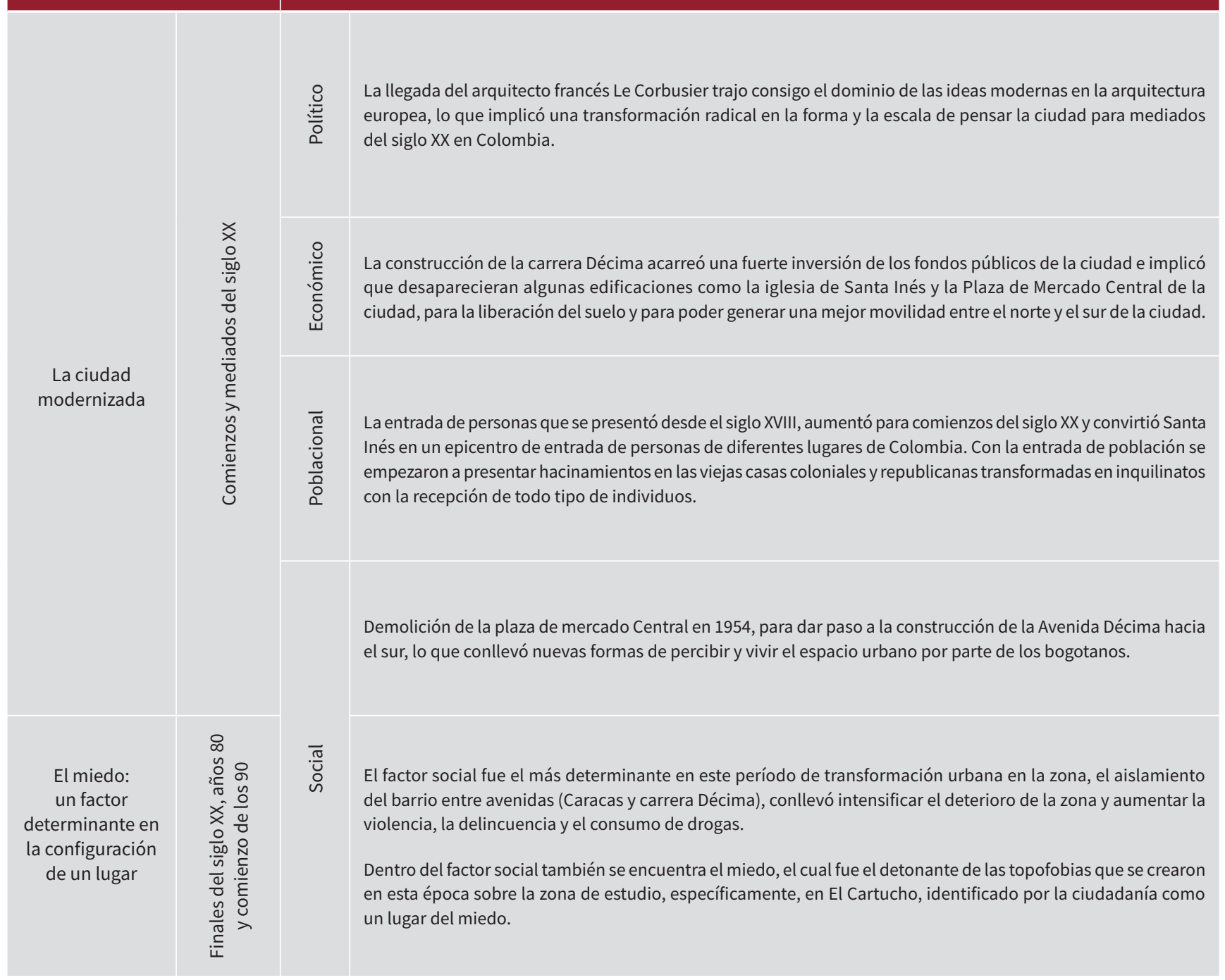

Fuente: Elaboración propia

Estos períodos permitieron obtener factores representativos que contribuyeron o fueron causantes de los diferentes cambios del paisaje urbano previos a 1998, y que, a su vez, se convirtieron en el referente y el punto de partida para la identificación de las problemáticas y los factores que han modelado el paisaje urbano del barrio durante el período 1998-2010; estos factores fueron: el religioso, el político, el económico, el social, el poblacional, el higienista y el legal.
Los cinco períodos permitieron analizar los cambios en el paisaje urbano durante cuatro siglos, un paisaje en el que dichos cambios se presentaron a un ritmo constante y que, como ya sugería Horacio Capel (2002), hacían mención a las formas como los sujetos entendían la realidad en la que vivían en un momento dado, reflejado en sus edificaciones y en los usos del suelo. 


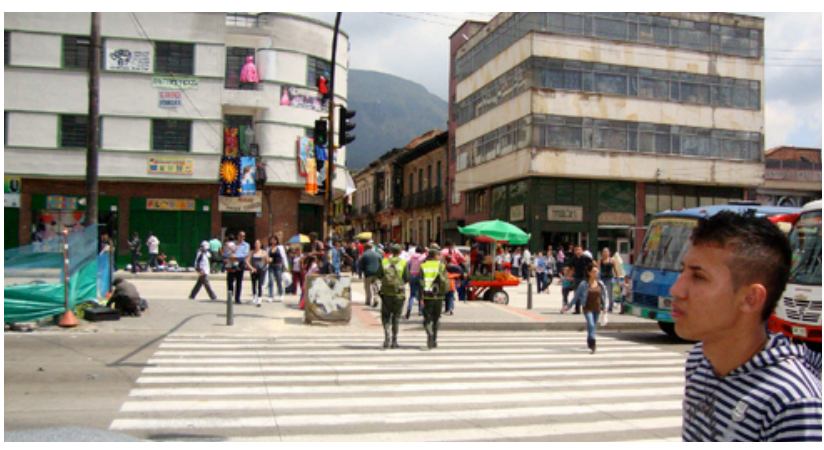

Figura 2. Actual carrera 10 con calle 10

Fuente: propia, 2011

Durante el período denominado Entre iglesias y creencias, la religiosidad fue un factor decisivo en el modelado del paisaje; más aún, con el antiguo monasterio e iglesia de Santa Inés y la orden de religiosas que resguardaban estas edificaciones, y que marcaban las dinámicas sociales de la época bajo la tarea evangelizadora de la Colonia, tarea que se vio amenazada durante el período Una aldea empezaba a vestir de ciudad, por un factor de tipo legal: la ley de desamortización de manos muertas para 1861, establecida por el presidente Tomás Cipriano de Mosquera, con la que se expropiaba de sus bienes a las comunidades religiosas del territorio colombiano, con el fin de liberar el suelo y darle una mejor funcionalidad, declarando dichos bienes como patrimonio de la nación, para luego ser subastados y obtener así un propietario privado.

Esta situación encajaba con la característica de normatividad del paisaje urbano trabajada por Yenny Real (2009), después de que las reglamentaciones a lo largo del tiempo determinan la forma del paisaje y constituyen un elemento esencial en su definición; en este caso, el factor religioso y dogmatizador iba perdiendo autoridad para la época, y ganaba más fuerza un factor de índole político y legal.

Santa Inés como barrio colonial nace entre un imaginario religioso, a la sombra de las grandes cúpulas de las iglesias de la capital. Sus habitantes eran conservadores y creyentes, fieles a las decisiones de la corona española, personas que se ajustaban con la tranquilidad de las casas de dos pisos con tejados en barro o calicanto; un paisaje contrario al del período catalogado El miedo: un factor determinante en la configuración de un lugar, en el que la imagen de los habitantes era el reflejo de las injusticias y la falta de reconocimiento del otro, huellas de lo que fue dejando el avance de la ciudad, donde las piezas que no encajan en el rompecabezas urbano debían ser ocultadas, "los individuos no admitidos se veían abocados a la marginación y a la utilización forzosa de los espacios públicos restantes" (Oliver-Frauca, 2006, p. 372). En este caso, el espacio fue El Cartucho, que recogió en su seno a individuos que transitaban entre las huellas de lo que en algún momento gozó del lujo y ahora se encerraba entre la apatía, el robo y la subsistencia del más fuerte; vivir o dejar de existir, sin que ello importase a alguien.
(...) Se llama el callejón de la muerte, era detrás del colegio luz de amor cerca de la bomba, (...), entonces yo estoy ahí, en ese callejón una mañana, cualquier las 10 , a las 11 o cualquier hora de esas estaba ahí, esa era (...) la carrera $12^{\mathrm{a}}$ algo así, (...) dicen que era el callejón de la muerte, era angostico, fuera de eso tenía una salida al otro lado, allá como a la octava, esa era subiendo por donde era una parte que se llamaba conteiner, el de la basura, entonces en esa cuadra del conteiner, ahí era, ahí estaba la bomba, un colegio y había una carrera que era como la $12^{\mathrm{a}}$ me parece (...) y ahí en ese campo, yo recuerdo que lo más terrible que he podido ver, es que hay dos muchachos y sube una señora, la esposa de uno de los jíbaros y ella iba con unos paquetes y a medida que subía la falda, se le subía la falda, la parte de atrás se le veían ya los interiores, entonces los chinos, eran dos muchachos jovencitos, echándole piropos ¡Mamacita! Y ella con ese afán, se devuelve el marido porque ya subía la policía, bueno era común, (...), yo pensé que me iba a matar porque yo estaba al lado de los muchachos y los mató a los dos chinos y fuera de eso me deja a mí vivo, yo veo al hombre desnudado, su rostro blanco, blanco, yo tengo muy presente esa cara y me dice el hombre, bótelos allá y pase por un ..., mejor dicho, quíteme eso y láveme eso ahí, pero no era si quiero o si no, era una orden, ¡no! yo jalando esos manes y jalándolos ahí pa' llevarlos allá, entonces le dije a otro que me ayudara, cuando me voy a subir me quedo con los tenis de ellos, me quedo con los tenis y le quito los tenis y las medias, ese era ya como mi trofeo, era mi primera cuota inicial de lo que estaba haciendo, otros subieron arriba a requisarlos, bueno ya los empelotan allá, entonces vengo y lavo eso, pero eso fue como un acto terrible porque los pelaos entre los zapatos tenían todo el dinero, le quité los zapatos al que tenía el dinero, pero fue una cuestión de impulso ahí, unas zapatillas. Pero eran jovencitos, pero ese acto entonces ahí la vida no tenía ningún sentido, era terrible, así era todo lo que se veía, las muertes, se agarraban entre los jíbaros y se mataban, bueno, pero la muerte de los drogadictos sí era muy frecuente, por lo que no pagaban una cuenta o por bobadas, la vida no tenía ningún sentido, creo que eso es como parte de eso y lo otro es un camino de indigencia, comer cosas de descomposición, esa vida es muy terrible, una cosa es pensar y hablar, pero otra cosa es vivir el tema de la drogadicción, mire lo que fue ese momento de ahí, yo viví mucho ahí. (Entrevista a Jorge Monroy, ex habitante de El Cartucho, abril 19 de 2011)

Para finales de la década de 1990, el habitante de la zona no era ya el mestizo, el criollo, el español ni, mucho menos, el cachaco; el paisaje lo personificaban los negocios entre el indigente, el reciclador, el jíbaro o la prostituta, quienes no se identificaban por vestir de una forma elegante y sofisticada, como en otras épocas: su vestimenta era sucia y los olores, desagradables. Individuos que eran parte de "espacios fragmentados a los que no todo el mundo puede acceder libremente, la cohesión del entorno urbano se debilita y la interacción entre los diversos colectivos se afeblece progresivamente" (Oliver-Frauca, 2006, p. 370). Paisaje que 
repercutió en la ciudadanía creando un imaginario del miedo al lugar, el rechazo a algo desconocido que se tiene cerca, pero lejos; lejos en el sentido de lo que suele ser repulsivo, angustioso y cargado de un fuerte contenido de degradación humana.

Kevin Lynch (1984) indica que el impacto negativo que produce el deterioro de un lugar en el vecindario impacta en la autoidentidad de este y de los sujetos. Los lugares, más que una creación física, son el tejido que adquieren los sujetos por medio de lo vivido y lo percibido, a lo que aludía Joaquín Bosque (1992): el ser humano comprende y percibe el espacio en el que vive desde su sentir en él, entrando a comparar y apreciar las diferencias a través de las vivencias propias o las de los otros, esos otros que pueden ser las narraciones de la gente en la calle, en el trabajo, en el transporte, o las de la familia o de los medios de comunicación, con imágenes que van creando límites mentales sobre determinados lugares en la ciudad.

Las casas que guardaban los diálogos revolucionarios y planes de arremetidas contra el poder español, y que buscaron con su arquitectura para la época republicana mostrar independencia política y económica, para los años ochenta y noventa del siglo XX se convirtieron en el resguardo de la indigencia de la ciudad, lo cual hacía ver que dentro de las transformaciones urbanas lo social era un factor que cada vez era más latente, pero no era asumido de forma concreta.

Durante la Colonia y parte de la República, en el segundo y tercer períodos identificados (Entrada y aumento de población y Una aldea empezaba a vestirse de ciudad), se evidencia el barrio como una fuerte senda comercial, que presentó una alta entrada de personas de diversos lugares del país, por causa de la violencia o por la intención de llegar a la capital a ofrecer sus productos, debido a que el barrio comunicaba la ciudad con el resto del país por la vieja vía a Honda llegando por el Puente de Aranda.

El aumento de la población hizo que a finales del siglo XIX apareciera la Plaza Central de Mercado, la cual vio desbordados sus propios límites por la cantidad de personas que seguían llegando de diferentes partes del país a ofrecer variedad de productos; el comercio era cada vez más grande, lo que implicó tener un espacio mucho más amplio; situación adherida al éxodo de las familias residentes en el barrio para los años veinte y treinta del siglo XX que empezaron a emigrar hacia el norte de la ciudad y dejaron atrás su hogar. Esta acción consolidó el lugar como un nodo de recepción de personas con bajos recursos que buscaban, al llegar a la capital, inquilinatos económicos en los cuales poder pasar la noche. Las grandes casonas empezarían a ofrecer este servicio, que con el paso del tiempo las degradó, siendo olvidadas por sus antiguos dueños y poco preservadas por sus nuevos residentes, panorama que ejemplifica lo dicho por Alberto Gómez (1984), en el sentido de que a finales de la década de 1940 se hizo necesario en la geografía prestar una mayor atención al factor humano como estructurador del paisaje, ya que es el sujeto quien con sus acciones lo va matizando y le va facultando un contenido.
El paisaje que contienen las ciudades latinoamericanas es una creación de, por y para el hombre, aunque en algunos momentos de la historia se observa cómo algunos intereses se van convirtiendo en individuales y desconocen lo colectivo; de ahí que esa aldea, que empezaba a vestirse de ciudad finalizando el siglo XIX y comienzos del XX, se insertará en un proceso de incorporación a la economía mundial y empezará a concebir la higiene como un factor modernizante y de progreso, que colisionaba de forma directa con las lógicas de ocupación y utilización de los espacios de la ciudad para la época.

Por lo anterior, en el período de La ciudad modernizada se arrasará con el convento y la iglesia de Santa Inés, al igual que con la Plaza de Mercado Central; principalmente con esta última, pues era una edificación que creaba imágenes de subdesarrollo expresadas en el desaseo y la falta de organización de los vendedores, y daría paso, a su vez, al avance de la carrera Décima hacia el sur de la ciudad, en el que, igualmente, se ven involucrados factores de corte económico, social y político, manifestados en una fuerte inversión por parte de los dineros públicos y la liberación del espacio público.

Además de la llegada del arquitecto francés Le Corbusier que establece el dominio de las ideas modernas en la arquitectura y el urbanismo en el país, empezando a privilegiar como lo señalaba William Montoya (2007) los discursos urbanísticos de las élites que llevaron a una transformación radical en la forma y escala de pensar la ciudad, escenario que luego se desbordará para finales del siglo XX y comienzos del siglo XXI, principalmente en el centro histórico.

\section{Problemáticas sociales y establecimientos de factores}

Respecto al desarrollo de los otros dos objetivos específicos que se refieren a la identificación de conflictos generados y a evidenciar los factores que han intervenido en el proceso de transformación urbana de la zona de estudio durante el período 1998-2010, se encuentra que una de las principales problemáticas fue la demolición de El Cartucho, debido a que esta intervención no solo llevó a la desaparición de edificaciones, sino a la movilización de sus habitantes hacia otros lugares de la ciudad, como la calle del Bronx, la L, la parte posterior de la central de mercados de Abastos y la Localidad de Bosa, entre otros espacios en los que se han ido fortaleciendo las actividades de consumo y delincuencia de la ciudad, en vista de que la evacuación no fue la adecuada.

La liberación del suelo para construir el parque Tercer Milenio no resguardó las dificultades de los habitantes; por el contrario, hizo que estas se dispersaran, situación que se relaciona con lo sugerido por William Montoya (2007) sobre que el consumo y la innovación urbana tienden, a lo largo de las últimas décadas, a pasar por alto el reconocimiento de 
la particularidad de los sujetos y los lugares, por la búsqueda de una homogenización que no se logra obtener en su totalidad. Dado que las diferencias no desaparecen, querer lograr una ciudadanía universal es impensable, por la diversidad de formas de entender la realidad de cada sujeto y cada pueblo; el indigente, el habitante de la calle, no pueden cambiar sus costumbres y sus hábitos de un día para otro, sino que esto conlleva un trabajo arduo de cooperación y reconocimiento por parte de la sociedad.

Francesc Muñoz (2008) expone cómo, aunque no es posible poder llegar a una ciudadanía universal, el discurso propio de lo global tiende a hacer de las diferencias algo comparable y medible, estandarizando los criterios para su comprensión, domesticando y encuadrando las diferencias en principio difíciles de leer y comprender, debido a su propia singularidad.

Ante los trabajos del profesor Carlos Mario Yori (2007) acerca de la ciudad desde el Plan de Ordenamiento Territorial (POT), cabe resaltar, en relación con lo señalado, que el POT no se ha podido realizar en Latinoamérica, por la falta de reconocimiento de quienes viven en la ciudad; no ha sido posible pasar de una democracia representativa a una democracia participativa que incluya al sujeto; por ello, el factor legal, que ha sido un arduo promotor del cambio, se ha caracterizado en el tiempo por distanciarse del factor social, algo evidente en los decretos de renovación urbana de la zona: los decretos 880 de 1998 y 346 de 2003 , que permitieron la demolición de las 16 manzanas del barrio Santa Inés anteriores a 1998 y el surgimiento del parque Tercer Milenio, sin tener en cuenta al habitante de calle.

Es así que para poder hablar de una verdadera renovación urbana desde el POT en la ciudad de Bogotá, se hace indispensable el fortalecimiento de las organizaciones sociales para llegar a una democracia participativa en las transformaciones urbanas que ha ido presentando el paisaje en los últimos años. Nada más peligroso para la ciudad que plantear una sola forma de ciudadanía, factor político que elimina la flexibilidad como consecuencia de la homogenización de las prácticas sociales, objetivo que se ha ido logrando, pero llevando a una crisis socio-cultural y forzando comportamientos en lo urbano que conllevan factores delictivos y de violencia de mayor tensión.

En consecuencia, el paisaje urbano que tienen hoy las 16 manzanas intervenidas del barrio lo impone el mercado antes que la necesidad del habitante, donde se quiso garantizar a la ciudadanía un imaginario de seguridad, escenario que es, a su vez, sinónimo de un alto control de las formas de actuar los sujetos dentro del espacio.

La pregunta ante este contraste entre el pasado y el presente es: ¿realmente los habitantes de Bogotá en la actualidad perciben el lugar como seguro y asequible? Aunque haya pasado a ser un gran parque, con amplios espacios y vigilado, el indigente sigue en él, y el miedo de los bogotanos aún se percibe cuando evitanentrar a lo que fue el sector de El Cartucho.

De igual forma, la información obtenida permite identificar algunos de los elementos de lectura urbana planteados por Kevin Lynch (1984); por ejemplo, las calles novena y décima convertidas hoy en límites entre dos espacios del barrio: el parque y la zona comercial de San Victorino, debido a que en los días hábiles el espacio entre ambas calles de norte a sur, o viceversa, implica un cambio notable en el ambiente, pues hacia el norte se observan un amplio colorido y multitud de gente acompañada de venta de productos de toda variedad en los almacenes y las calles; sonidos, personas que van y vienen, las calles se atumultúan, es como si la Plaza de Mercado Central de comienzos del siglo XX en la ciudad aún existiera, en vista de que las ventas, al igual que en la plaza, se ven desbordas hacia las calles. El vendedor ambulante expone sus productos $y$ los ofrece a vox populi a quienes van pasando por el lugar; San Victorino, dentro del paisaje, mantiene aún la diferencia, la diversidad, nodo poblacional que en sus dinámicas sociales se resiste al cambio.

Situación contraria hacia el sur de la misma calle, donde el silencio gobierna; aunque cruzan personas, estas no se detienen en su andar en el parque, el objetivo es cruzar de la carrera Décima a la Avenida Caracas, o viceversa, lo más rápido posible; no obstante, dicha situación no se mantiene los fines de semana, cuando los habitantes de las zonas cercanas, como el barrio San Bernardo y el Conjunto Residencial Campo David, llegan a pasar su descanso en el parque jugando, leyendo, dialogando, usando las fuentes de agua como piscinas públicas para los niños. En fin, el paisaje toma otro tinte, adquiere colores diferentes de los de las rutinas diarias de la semana.

Hacia el nororiente del parque se encuentra una especie de tianguis ${ }^{5}$ de artículos de segunda, espacio de bastante confluencia de personas, y que, al igual que las fuentes, es un elemento reconfigurado en la utilización del parque, independientemente de lo establecido en la normatividad urbana.

El lugar va adquiriendo nuevas funciones por las dinámicas y las relaciones tejidas por los sujetos, pero demarcan diferentes momentos de movilidad y asequibilidad entre los días hábiles y los fines de semana. De la misma manera, en el lugar se van encontrando huellas del habitar del indigente: la suciedad, el desorden y la imagen de inseguridad.

Respecto a las funciones y los usos de la zona comercial de San Victorino, estos se mantienen, aunque cabe resaltar la prostitución en la plaza de la Mariposa (plaza de San Victorino), que recibe su nombre de

5 La palabra hace referencia al mercado de objetos usados que se realiza sin una organización espacial. 
las niñas entre los 13 y los 17 años que prestan servicios sexuales, las mariposas, no identificables a simple vista por la cantidad de gente que concurre a la plaza.

En conclusión, el paisaje urbano de la zona es en la actualidad el resultado de diferentes épocas, pues la historia no tiene fin, siempre está rehaciéndose. Por ello, hablar de la conservación total del paisaje urbano no tiene sentido; empero, se esperaría que dicha creación no vaya en contra de su mismo creador, como afirmaba Gordon Cullen (1974), el paisaje es un medio viviente que debe satisfacer a quienes viven y trabajan en él o lo contemplan.

El cartucho era un lugar de drogadictos, era como la zona franca que siempre ha habido en Bogotá para el consumo de drogas, como lo es ahora la $\mathrm{L} o$ aquí el San Bernardo que está pues con sus dos cuadras de zona de tolerancia para el consumo de droga, de todas maneras, eso no lo pueden terminar así, porque ¿a dónde se va albergar la gente? (Entrevista a Jorge Monroy, ex habitante de El Cartucho, abril 19 de 2011)

\section{Algunas conclusiones}

La legalidad es un factor decisivo en la transformación del paisaje urbano que se hace evidente en los decretos de renovación urbana de la zona que han aprobado la demolición de edificaciones y el surgimiento de otras. Específicamente, los decretos 880 de 1998 y 346 de 2003, que dieron la apertura al cambio no solo de edificaciones, sino de las dinámicas sociales de la zona de estudio.

De igual forma, la búsqueda de nuevos espacios que generarán apertura a nuevos habitantes y vecindarios en zonas que no habían sido anexadas a la lógica de modernización de la ciudad, y que se encuentran dentro del centro histórico (zona importante para explotar en el tema turístico), se convierten en tema de la renovación desde factores económicos y sociales, donde la seguridad se convierte en un producto de venta que garantiza a los sujetos que se sientan tranquilos y vigilados, sinónimo de un alto control de las formas de actuar dentro de la ciudad.

Además, como ya se ha manifestado, uno de los objetivos recurrentes en las transformaciones del barrio antes y después de 1998 ha sido la recuperación del espacio público, que con la entrada del Sistema Masivo de Transporte Transmilenio por la carrera Décima, hará que las ventas formales e informales de los vendedores de este corredor vial de la ciudad se modifiquen; sin embargo, es difícil poder dejar atrás el carácter bullicioso y congestionado que desde épocas pasadas ha caracterizado esta zona.
Cabe resaltar que en todo este proceso de cambio, las organizaciones sociales no se tuvieron en cuenta, lo cual ha negado la posibilidad de una democracia participativa en el Plan de Ordenamiento Territorial de la ciudad. Esta situación llevó a que los cambios realizados en la antigua zona de El Cartucho no lograran su objetivo principal : la apertura a nuevos habitantes con un poder adquisitivo alto, pues perdura el imaginario del miedo, la desconfianza en una zona que por mucho tiempo se mantuvo al margen del progreso de la ciudad capital, y que aún recoge el caminar del habitante de calle, quien recorre sin falta los distintos lugares del parque, en vista de que el factor político se ha centrado en el interés individual antes que grupal, descalificando las necesidades de quien habita, para dar prioridad al mercado mundial.

Por otro lado, la memoria se convierte en este trabajo en un factor de reivindicación por el lugar y resistencia al olvido. Querer hablar sobre la memoria como factor de reivindicación y resistencia, solo lleva a justificar lo humano de esta acción, resultado de la afiliación emocional de los sujetos para poder actuar y contarse y recontarse a sí mismos y a los demás dentro de un tiempo y un espacio determinados, para justificar su existencia, en vista de que quien no se narra a sí mismo desde sus experiencias como integrante de un grupo social, no existe.

En conclusión, lo anterior permite afirmar que los factores encontrados en los cinco períodos de transformación urbana anteriores a 1998 permanecen en la transformación del paisaje de la zona de estudio entre 1998 y 2010 (económico, político, social y legal); sin embargo, la resistencia al cambio desde el mismo paisaje y los sujetos que lo conforman ha hecho que tales factores adquieran otras formas de actuar y de ser entendidos, pero, finalmente, tienen el mismo objetivo.

Por último, el parque aún resguarda al indigente y San Victorino mantiene su colorido en jergas y acciones de venta y delictivas que no son fáciles de borrar con un aparente cambio morfológico. De ahí la importancia de sugerir un quinto factor, no de transformación, sino de conservación del lugar: la memoria que reivindica el lugar, las experiencias y las relaciones efectuadas en él por diferentes generaciones. 


\section{Referencias}

Bosque, J. (1992). Prácticas de geografía de la percepción y de la actividad cotidiana. Barcelona, España: Oikos-tau.

Capel, H. (2002). La morfología de las ciudades: I. Sociedad, cultura y paisaje urbano.Barcelona: Ediciones del Serbal.

Carter, H. (1974). El estudio de la geografía urbana. Adri y P. B. Van Breda (Trads.). Madrid: IEAL (Institución de Estudios de Administración Local).

Castells, M. (1974). La Cuestión Urbana. México, España y Argentina: Siglo XXI.

Cullen, G. (1974). El paisaje urbano: tratado de estética urbanística. Barcelona: Blume.

Fernández, A. (1990). La metrópoli vacía: aurora y crepúsculo de la arquitectura en la ciudad moderna. Barcelona: Anthropos.

Gómez, A. (1984). Geografía Social y Geografía del Paisaje. Revista Geocrítica. Cuadernos Críticos de Geografía Humana (49) 1-34. Universidad de Barcelona.

Lefebvre, H. (1970). La renovación urbana. Madrid: Alianza.

Lynch, K. (1984). La imagen de la ciudad. Versión castellana de Enrique Luis Revol, Barcelona: Gustavo Gili.

Montañez, G. (2001). Razón y pasión del espacio y el territorio. En AA. VV. Espacio y Territorio. Razón, Pasión e Imaginarios(pp. 15-32). Bogotá: Red de estudios de Espacio y Territorio, RET. Universidad Nacional de Colombia.

Montoya, J. (2006). Cambio urbano y evolución discursiva en el análisis de la ciudad latinoamericana: De la dependencia a la globalización. Serie de trabajos en geografía. Universidad Nacional de Colombia, Facultad de Ciencias Humanas.
Montoya, J. (2007). Releyendo la ciudad latinoamericana, cambio urbano y cambio morfológico en Bogotá. Cuadernos de geografía, (16) 9-18. Revista del Departamento de Geografía. Universidad Nacional de Colombia, Facultad de Ciencias Humanas.

Morris, I. (2010). En un lugar llamado el cartucho (crónica). Alcaldía Mayor de Bogotá. Cultura, Recreación y Deporte. Instituto Distrital del Patrimonio Cultural, investigación.

Muñoz, F. (2008). Urbanalización. Paisajes comunes, lugares globales. Barcelona: Gustavo Gili.

Oliver-Frauca, L. (2006). La ciudad y el Miedo. En J. Nogue \&J. Romero (Eds.). Las Otras Geografías (pp.369-388) . Valencia: Tirant lo Blanch.

Páramo, P. (2007). El significado de los lugares públicos para la gente de Bogotá. Bogotá, Colombia: Nomos..

Real, Y. (2009). Paisaje urbano. Estudio patrimonial del eje de la Carrera $7^{a}$ de Bogotá entre el centro fundacional y Chapinero. Bogotá, D. C.: Pontificia Universidad Javeriana. 1a ed.

Whittaker, J. (1968). Psicología. Luis Méndez (Trad.). México D.F.: Editorial Interamericana.

Yori, C. (2007). Topofilia o la dimensión poética del habitar.Bogotá D.C.: Pontificia Universidad Javeriana. 